\title{
Familial interstitial Xq27.3q28 duplication encompassing the FMR1 gene but not the MECP2 gene causes a new syndromic mental retardation condition
}

\author{
Marlène Rio $^{\star, 1}$, Valérie Malan ${ }^{1}$, Sarah Boissel ${ }^{1}$, Annick Toutain ${ }^{2}$, Ghislaine Royer ${ }^{1}$, Stéphanie Gobin ${ }^{1}$, \\ Nicole Morichon-Delvallez ${ }^{1}$, Catherine Turleau ${ }^{1}$, Jean-Paul Bonnefont ${ }^{1}$, Arnold Munnich ${ }^{1}$, Michel Vekemans ${ }^{1}$ \\ and Laurence Colleaux ${ }^{1}$
}

X-linked mental retardation is a common disorder that accounts for $5-10 \%$ of cases of mental retardation in males. Fragile $X$ syndrome is the most common form resulting from a loss of expression of the FMR1 gene. On the other hand, partial duplication of the long arm of the $X$ chromosome is uncommon. It leads to functional disomy of the corresponding genes and has been reported in several cases of mental retardation in males. In this study, we report on the clinical and genetic characterization of a new X-linked mental retardation syndrome characterized by short stature, hypogonadism and facial dysmorphism, and show that this syndrome is caused by a small Xq27.3q28 interstitial duplication encompassing the FMR1 gene. This family broadens the phenotypic spectrum of FMR1 anomalies in an unexpected manner, and we suggest that this condition may represent the fragile $X$ syndrome «contre-type». European Journal of Human Genetics (2010) 18, 285-290; doi:10.1038/ejhg.2009.159; published online 21 October 2009

Keywords: X-linked mental retardation; chromosome duplication; FMR1

\section{INTRODUCTION}

$\mathrm{X}$-linked mental retardation (XLMR) is a heterogeneous group of syndromic and nonsyndromic disorders. Although the most common cause of XLMR is an expansion of an unstable trinucleotide repeat in the $5^{\prime}$-UTR of the FMR1 gene that causes the fragile X syndrome, ${ }^{1}$ mutations in more than 80 other genes have also been involved in XLMR. ${ }^{2}$ Yet, linkage data and mutation screening of known XLMR genes strongly suggest that many more are to be discovered. ${ }^{3}$ Moreover, recent data suggest that novel mechanisms likely account for unknown genetic defects. This is why the search for novel XLMR mutations was recently shifted toward a high-throughput sequence analysis of brain-expressed X-chromosomal miRNA genes, ${ }^{4}$ or all genes on the $\mathrm{X}$ chromosome, ${ }^{5}$ as well as screening of submicroscopic imbalances by array-comparative genome hybridization (array-CGH). ${ }^{6-8}$

In this study, we report on the molecular and clinical characterization of a small interstitial Xq27.3q28 duplication encompassing the FMR1 gene in a large X-linked syndromic mental retardation family.

\section{MATERIALS AND METHODS}

Patients

Patients were referred to the Genetic Department of the Necker-Enfants Malades hospital for investigating their developmental delay. Blood samples were obtained from the probands and their parents after obtaining informed consent, and genomic DNA was isolated from blood leukocytes using the Nucleon kit (Amersham, UK) according to the manufacturer's instructions.

\section{Genotyping}

Fluorescent genotyping was carried out as previously described. ${ }^{9}$ Polymerase chain reaction (PCR) amplification of genomic DNA from parents and patients (100 ng) was undertaken separately. PCR products were then pooled according to their size and labeling, and were analyzed on a capillary electrophoresis system (ABI 3130 Applied Biosystems), and alleles were identified using GeneScan and Genotyper softwares.

\section{Standard and molecular karyotyping}

Standard karyotyping using GTG and RHG banding analysis and the highresolution R-banding technique were performed on patients and parental peripheral blood lymphocytes according to standard procedures.

Array CGH analysis was performed using the CytochipTM V2 Microarray (BlueGnome, AmpliTech) with a resolution of $1 \mathrm{Mb}$ according to the manufacturer's instructions.

\section{Fluorescence in situ hybridization}

BACs were selected from several databases (UCSC, University of California, Santa Cruz http://genome.ucsc.edu/ and NCBI, the National Centre for Biotechnology Information http://www.ncbi.nlm.nih.gov/). FISH experiments were performed on chromosome preparations as described previously. ${ }^{10}$ 
Metaphase spreads were prepared from patient-derived lymphocytes using standard procedures. The human genomic clones from RPCI BAC and PAC libraries were obtained from BACPAC resources (http://bacpac.chori.org/).

\section{$\mathrm{X}$-inactivation analysis}

$\mathrm{X}$-chromosome-inactivation patterns in carrier females were performed on genomic DNA extracted from white blood cells at the FMR1 locus as previously described. ${ }^{11}$

\section{RESULTS}

\section{Clinical presentation}

We had the opportunity to ascertain a French family in which three male members presented with similar clinical findings of mild mental retardation, hypogonadism and short stature (Figures 1-2 and Table 1). Individual III.1 was born at 35 weeks of gestation after a normal pregnancy and delivery. Birth weight was $1500 \mathrm{~g}(<5$ th percentile), birth length was $43 \mathrm{~cm}$ (10th percentile) and head circumference was $30 \mathrm{~cm}$ (10th percentile). The neonatal period was complicated by hypotonia, failure to thrive and regurgitations, which resolved by 3 months of age. He walked alone at 16 months, was toilet trained at 2 years and had no speech delay. At 5 years of age, poor motor performances were noted. He had mild learning difficulties and left school at 12 years. He was noted to have undescended testis in childhood and underwent bilateral orchidopexy at 7 years. Subsequently, primary hypogonadism was diagnosed and testosterone therapy was prescribed. On examination at 35 years, his height was $149 \mathrm{~cm}(-4 \mathrm{SD})$, whereas his predicted final height was $168 \mathrm{~cm}$. His weight was $46 \mathrm{~kg}(+1 \mathrm{SD})$ and his head circumference was $54.5 \mathrm{~cm}$ ( -1 SD). He had small hands and feet, and showed mildly dysmorphic facial features with deep-set eyes, a bulbous nasal tip and thin lips (Figure 2). He also had a high-pitched voice, sparse body hair, abdominal adiposity and bilateral small testes ascribed to primary testicular failure confirmed by a subsequent endocrine investigation (Table 1). He was able to read and write. He was highly social and communicated verbally with good sentence structure. He had no abnormal behavior. He was unemployed, lived semi-independently, was independent for tasks of daily life but needed help to prepare food and he was unable to look after his financial affairs. No abnormalities were noted on brain CT-scan and brain magnetic-resonance imaging performed at 35 years. Complete skeletal radiographs did not show any abnormalities. Blood karyotype was normal. Fragile X was ruled out with the detection of one trinucleotide repeat expansion of normal size (44) and no abnormal methylation.

His maternal uncle (II.3), was born at term with a low birth weight ( $2400 \mathrm{~g}, 5$ th percentile). His clinical features were similar to those of his nephew, as shown in Table 1 and Figure 2. He had mild learning difficulties, was able to read and write and to communicate fairly well. He worked 12 years as a worker in a factory. When examined at 59 years, his height was $150 \mathrm{~cm}(-4 \mathrm{SD})$, his weight was $63 \mathrm{~kg}(+3 \mathrm{SD})$ and his head circumference was normal $(56 \mathrm{~cm})$. Neurological examination showed mildly increased reflexes. He had a high-pitched voice, sparse body hair, overweight with truncal obesity (BMI 28), gynecomastia and small testis. He also had small hands and feet and mildly dysmorphic features (Figure 2).

Individual III.4 was born at 38 weeks with intra-uterine growth retardation (weight $2400 \mathrm{~g}$ (5th percentile), length $43 \mathrm{~cm}(<5$ th percentile) and head circumference $32 \mathrm{~cm}$ (5th percentile)). His clinical features were similar to those of his cousin and his uncle (Table 1 and Figure 2). At 7 years of age, he had orchidopexy for undescended left testis. He was in good health as a child, but was small, with height at $-4 \mathrm{SD}$ ( $1 \mathrm{~m}$ at 7 years) and weight at $16.4 \mathrm{~kg}$ $(-2 \mathrm{SD})$. Endocrine testing at this time revealed a markedly delayed bone age ( $2 \frac{1}{2}$ years) but no growth hormone deficiency. He was said to have idiopathic short stature, but was nevertheless given Growth Hormone. Subsequently, he was found to have testosterone deficiency because of primary testicular failure and received testosterone treatment. Early psychomotor development was normal but he always had poor motor performances, was slow in his movements, ran with

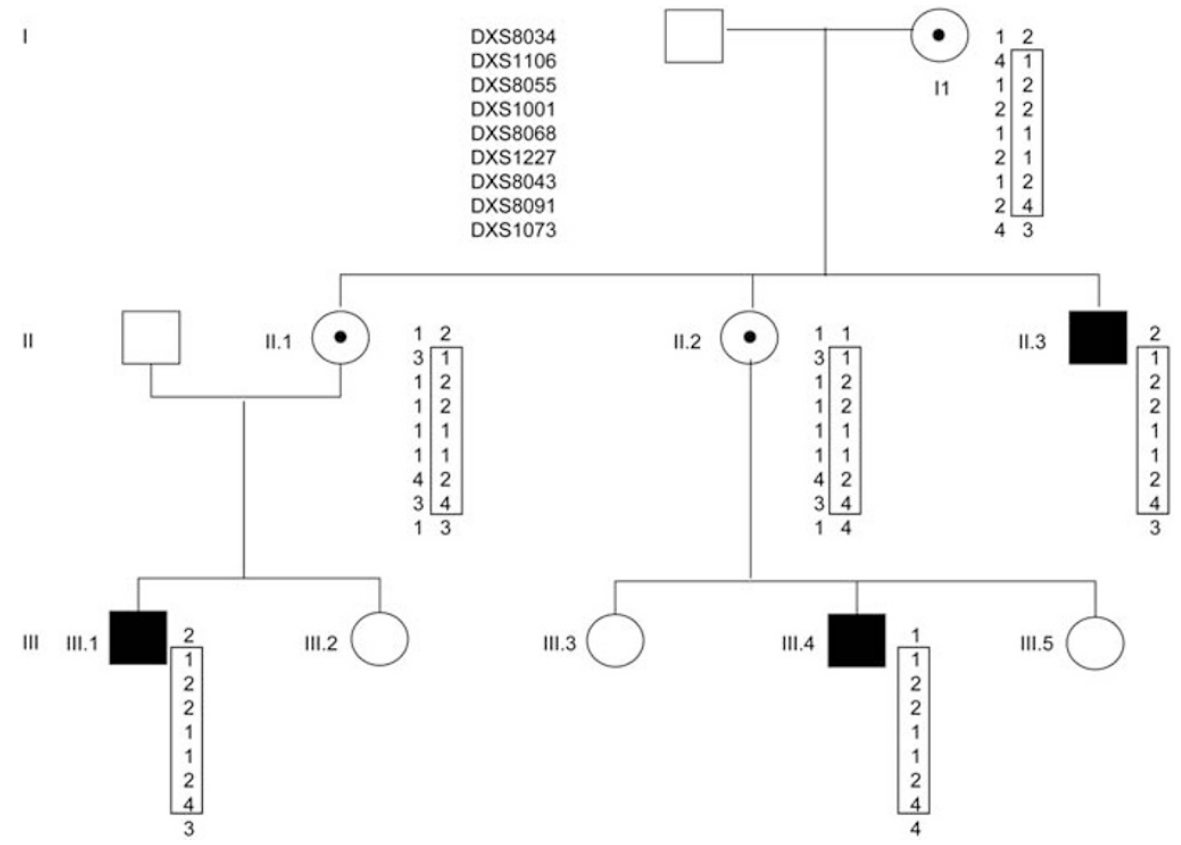

Figure 1 Two-generation genealogy of the family. Black symbols indicate the affected individuals related through their clinically normal mothers. Genotyped markers are from centromere to telomere. 


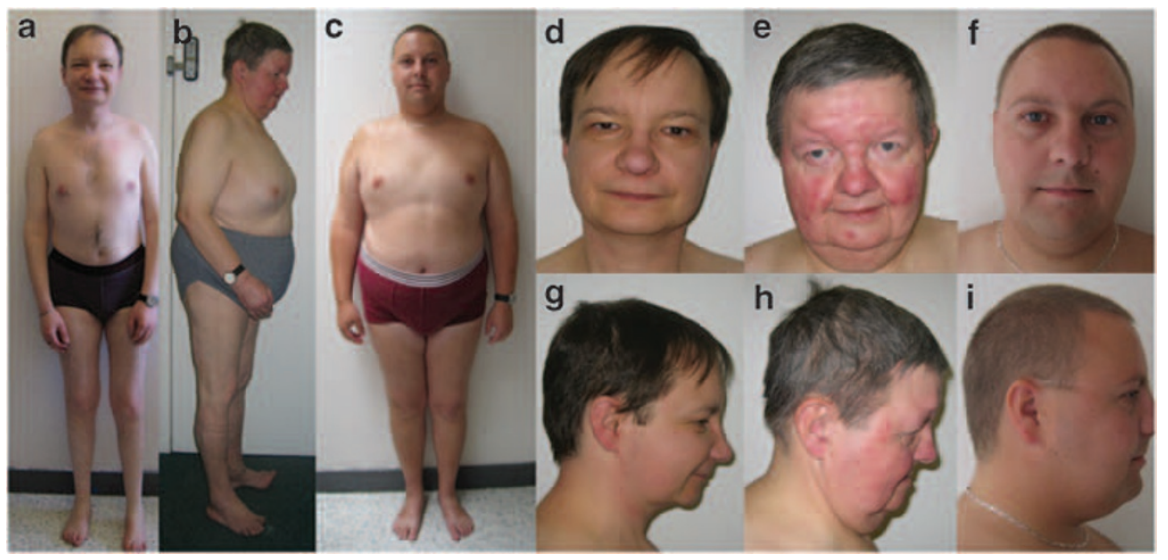

Figure 2 Photographies and facial features of affected individuals. a, d, g: Individual III.1, b, e, h: individual II.3, c, f, i: individual III.4. Note truncal obesity and sparse body hair. Similar facial features include deep-set eyes, bulbous nasal tip and thin lips.

Table 1 Clinical findings of affected individuals

\begin{tabular}{|c|c|c|c|}
\hline & III. 1 & 11.3 & III.4 \\
\hline \multicolumn{4}{|l|}{ Developmental history } \\
\hline IUGR & + & + & + \\
\hline Failure to thrive & + & + & + \\
\hline Walking (months) & 16 & 24 & 22 \\
\hline Mild learning difficulties & + & + & + \\
\hline Good verbal skills & + & + & + \\
\hline $\begin{array}{l}\text { Orchidopexy for } \\
\text { undescended testis }\end{array}$ & + & + & + \\
\hline Age at examination & 35 years & 59 years & 29 years \\
\hline Height in cm (SD) & 149 (-4 SD) & $150(-4 \mathrm{SD})$ & $157.5(-2.5 \mathrm{SD})$ \\
\hline $\begin{array}{l}\text { Head circumference } \\
\text { in } \mathrm{cm}(\mathrm{SD})\end{array}$ & 54 & 56 & 55 \\
\hline Small hands and feet & + & + & + \\
\hline Dysmorphic features & + & + & + \\
\hline Small testes & + & + & + \\
\hline Testicular volume & $<1 \mathrm{ml}$ & $<0,5 \mathrm{ml}$ & $<4 \mathrm{ml}$ \\
\hline \multicolumn{4}{|l|}{ Endocrine investigation } \\
\hline FSH $(1,5-14 \mathrm{mUl} / \mathrm{ml})$ & 65.2 & 16.4 & 21.7 \\
\hline $\mathrm{LH}(1,2-10 \mathrm{mUl} / \mathrm{ml})$ & 23.68 & 11.94 & 3.7 \\
\hline Testosterone $(2,5-10 \mathrm{ng} / \mathrm{ml})$ & 2.67 & 0.54 & 1.30 \\
\hline Inhibine B (80-400 pg/ml) & $<15$ & $<15$ & $<10$ \\
\hline IGF1 (100-247 ug/I) & 182 & 97 & 118 \\
\hline
\end{tabular}

difficulty and was described as having amyotrophy of the lower legs. He had mild learning difficulties at school, was able to read and write and to communicate, but was unable to work in adulthood. At the age of 29 years, his height was $157.5 \mathrm{~cm}(-2.5 \mathrm{SD})$, his weight was $81.2 \mathrm{~kg}$ $(+2.5 \mathrm{SD})$ and he had a normal head circumference $(55 \mathrm{~cm}) . \mathrm{He}$ had small hands and feet, truncal obesity (BMI 32) and mildly dysmorphic facial features (Figure 2). He also had a high-pitched voice and bilateral small testis. He was unable to look after his financial affairs and to live independently, but he successfully passed his driving test. Mutation screening in the genes SOX3, PHF6 and CUL4B was negative.

Obligate carrier females (individuals I.1, II.1, II.2) had neither abnormal findings nor learning difficulties, but all of them presented with a short stature $(148,148$ and $145 \mathrm{~cm}$, respectively) and early menopause between 39 and 40 years of age.

\section{Molecular analyses}

Because the pedigree of the family was consistent with X-linked recessive inheritance, linkage analysis was performed on three affected males and obligate carrier females. A panel of 25 polymorphic microsatellite markers spanning the $\mathrm{X}$ chromosome was genotyped and showed putative linkage to a 50-Mb-long region between DXS1106 (in Xq22.2) and DXS8091 (Figure 1).

To rule out the hypothesis of a chromosomal rearrangement, we performed array-CGH on DNA from patient III.1 using the Cytochip V2 Microarray (BlueGnome, AmpliTech). We identified a small duplication of the long arm of chromosome X. A total of 15 BACs (RP3-433G13, RP6-224C24, RP11-37P24, RP11-161L9, RP11-75A14, RP11-64L19, RP11-242E3, RP5-937E21, RP13-406D21, RP11-413L16, RP5-892C22, RP11-45D17, RP11-329E24, RP11-274C1 and RP114D6) spanning a region of $5.1 \mathrm{Mb}$ from Mb positions 146479822 (Xq27.3) to 151603959 (Xq28) had an enhanced $\log 2$ intensity ratio, whereas both RP11-226B15 and RP11-76K17 clones had a normal ratio. Metaphase and interphase FISH analyses on leukocytes confirmed the presence of the intrachromosomal duplication. The duplication segregated with the disease in the family, was identified in obligate carriers and was also identified in individuals III.3 and III.5. This duplication was not visible on routine chromosome analysis, even when the karyotype was reexamined with particular attention to this region. In addition, no other significant chromosomal imbalance was detected.

Finally, we investigated the $\mathrm{X}$-inactivation profile in all female carriers. Three out of five (I.1, III.3 and III.5) showed a completely skewed inactivation. Moreover, methyl-sensitive PCR analysis indicated that $100 \%$ of their cells had inactivated the duplicated $\mathrm{X}$ chromosome. The two remaining carriers (II.1 and II.2) showed a random X-inactivation profile (60/40 and 70/30, respectively).

\section{DISCUSSION}

Partial duplications of the long arm of the $\mathrm{X}$ chromosome are rare and have been mainly described in males with severe mental retardation/ developmental delay. ${ }^{12,13}$ Usually, they are inherited from heterozygous mothers in whom preferential inactivation of the $\operatorname{dup}(\mathrm{X})$ chromosome leads to a skewed X-inactivation pattern and results in a normal or mildly abnormal phenotype. ${ }^{14}$ By contrast, structural $\mathrm{X}$ duplication in XY males results in functional disomy, and excess gene dosage leads to an abnormal phenotype. Until recently, most cases of functional disomy have been detected using standard cytogenetic 
methods because of intrachromosomal duplications, an unbalanced $\mathrm{X} / \mathrm{Y}, \mathrm{X}$ autosome translocation or $\mathrm{X}$ pericentric inversion. The availability of the array-comparative genomic hybridization (array-CGH) technique has tremendously increased the ability to detect cryptic interstitial chromosome $\mathrm{X}$ imbalances, as illustrated by duplications of the MECP2 gene causing severe mental retardation and progressive neurological symptoms in males. ${ }^{15}$

In this study, we report an Xq27.3q28 5.1 Mb-long interstitial duplication segregating in a large family with syndromic mental retardation. The three affected males present with mild mental retardation, short stature, bilateral testicular ectopia and hypogonadism, as well as phenotypic features likely caused by testosterone deficiency (that is, gynecomastia, decreased pilosity on the body and high-pitched voice). Hypogonadism, one of the striking clinical features observed in our patients, is peripheral in origin, with elevated gonadotrophins and low testosterone levels. Hypogonadism has been described in several known syndromic forms of XLMR, especially in the Borjeson-Forssman-Lehmann syndrome ${ }^{16}$ (MIM:301900), Cabezas syndrome ${ }^{17}$ (MIM:300354) and the Wilson Turner syndrome $^{18}$ (MIM:309585), which have been mapped, respectively, to Xq26.3, Xq23 and Xp21.1-q22. However, our patients do not fulfill the clinical criteria of any of these conditions. First, none of them has the large ears, fleshy earlobes and small penis usually observed in the Borjeson-Forssman-Lehmann syndrome. Second, the occurrence of short stature with small testes, obesity and normal head circumference

Table 2 Summary of clinical details of patients previously reported with interstitial $\mathrm{Xq}$ duplications encompassing the $\mathrm{Xq} 27.3-\mathrm{Xq} 28$ region

\begin{tabular}{lccc}
\hline & Lachlan et al 2004 & Gecz et al 199935 \\
& Patient 1 & Patient 2 & \\
\hline Duplication Xq region & Xq27.2-Xq28 & Xq27.1-Xq28 & Xq26-Xq28 \\
Inheritance & De novo & Maternal & Maternal \\
Duplication size & $7.7-8.8 \mathrm{Mb}$ & $9.1-10.2 \mathrm{Mb}$ & \\
Birth weight & $2830 \mathrm{~g}(<9$ th) & $2950 \mathrm{~g}(9 \mathrm{th})$ & $2300 \mathrm{~g}$ \\
Developmental delay/MR & Severe & Moderate & Severe \\
Growth failure & $?$ & - & + \\
Microcephaly & + & + & + \\
Cryptorchidism & - & Unilateral & + \\
Obesity & $?$ & + & + \\
\hline
\end{tabular}

raises the issue of CULAB mutations. Yet, neither tremor, aggressive outbursts nor seizures was reported in our family. Third, the Wilson Turner syndrome could also have been discussed as Wilson Turner male patients often present with mild-to-moderate mental retardation, gynecomastia, small or undescended testes and obesity. However, endocrinological investigations in these patients suggest secondary rather than primary gonadal insufficiency.

Largely, 20 male patients with interstitial duplications of the long arm of chromosome X have been reported in literature. ${ }^{19-34}$ Yet, interstitial duplication encompassing the Xq27.3-Xq28 region has been reported in only three patients. ${ }^{35,36}$ The probands were males and duplication was detected using routine cytogenetic analysis. Unfortunately, a detailed clinical description of these patients is not included in the reports. The described clinical features are summarized in Table 2. Moderate-to-severe MR was observed in all cases. In addition, as observed in our patients, two cases were obese and had cryptorchidism, but no mention of primary testicular failure, one of the most relevant findings in our patients, was made. These three patients presented with microcephaly, a feature not observed in our family. Differences in size and position of individual duplications, disruption of various genes or position effects might explain this wide phenotypic variability.

Recently, an Xq28 duplication encompassing the MECP2 gene was found to cause severe mental retardation associated with progressive spasticity, axial and facial hypotonia, seizures and recurrent infections in males. ${ }^{15}$ By contrast, the duplicated segment in our patients encompasses 28 genes but does not include the MECP2 gene and causes a completely different clinical phenotype. Among the duplicated genes, several are of particular interest (Figure 3). Loss-offunction mutations of FMR1 and FMR2 genes are the cause of FRAXA syndrome (MIM:309550) and FRAXE syndrome (MIM:309548), respectively. The aneusomic region also contains the IDS gene responsible for the Hunter Syndrome (MIM309900) and the MTM1 gene responsible for X-linked myotubular myopathy (MIM310400). Whether functional disomy of any of these genes, disruption of genes at the break points of duplication or position effects are the major causative factor for mental retardation in our patients remains speculative. Yet, a twofold higher iduronate sulfatase enzyme activity was observed in peripheral leukocytes from individual III.4 when compared with control samples (data not shown), supporting the hypothesis of a functional disomy. As FMR1 status analysis in the probands revealed a stable expansion of the CGG repeat without abnormal methylation, we suggest that the duplication may also result

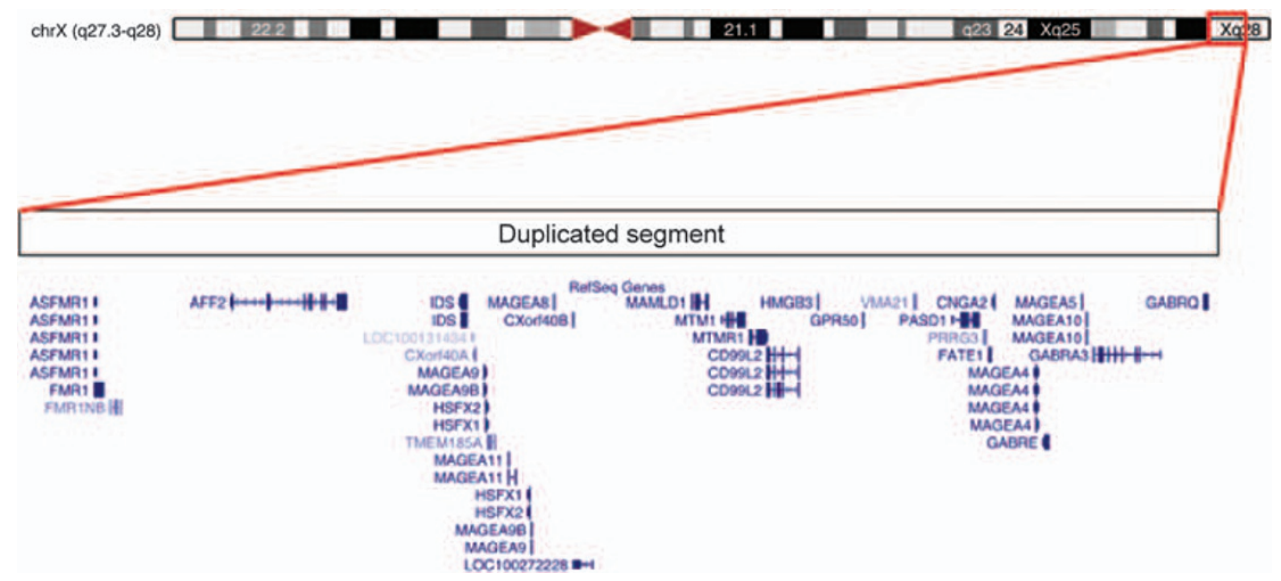

Figure 3 Schematic representation of chromosome $\mathrm{X}$ indicating the duplicated region. 
in increased FMR1 transcript expression. Interestingly, several features such as short stature or small testis are contrary to those observed in the fragile $\mathrm{X}$ syndrome. ${ }^{37}$ Similarly, although fragile $\mathrm{X}$ cases have severe speech delay, our patients had good verbal performance. Interestingly, some of these findings are reminiscent of what is observed in transgenic mice. ${ }^{38}$ Indeed, although Fmrl knockout mice showed increased locomotor activity suggesting increased exploratory behavior, FMR1 YAC transgenic mice showed low levels of locomotor activity suggesting decreased exploratory behavior. Similarly, the presence of the FMR1 transgene not only rescues the macroorchidism phenotype in the knockout animals, but FMRP overexpression results in reduced testis weight in wild type.

It is worth noting that all female carriers fulfill the diagnostic criteria of premature ovarian failure (POF) defined by hypergonadotropic ovarian failure before 40 years of age. ${ }^{39-41}$ This could be a direct consequence of chromosome rearrangement. X-chromosome rearrangements are known to lead to POF because of the presence of unsynapsed regions that might increase apoptosis and reduce the number of ovarian follicles. ${ }^{42}$ Alternatively, early menopause could also be a consequence of FMR1 overexpression. Indeed, normal carriers of FMR1 premutation are known to have a significantly higher frequency of POF. Moreover, expansion of the FMR1 CGG repeat represents the most common risk factors causing ovarian dysfunction. ${ }^{43}$ The risk increases with increasing length of the repeat, suggesting a toxic effect of the premutated mRNA itself, which might sequester CGG binding proteins that are important for RNA processing. Similarly, FMR1 gene overexpression because of Xq27.3q28 duplication could result in ovarian dysfunction.

In conclusion, this study reports the first familial case of an Xq27.3q28 interstitial duplication encompassing FMR1 and FMR2 genes. This chromosomal imbalance is responsible for a novel clinical phenotype characterized by mild mental retardation, short stature and hypogonadism because of primary gonadal failure. On the basis of these findings, we suggest that this chromosomal imbalance is responsible for a novel clinically recognizable syndrome that may represent the fragile X syndrome 'contre-type'.

\section{CONFLICT OF INTEREST}

The authors declare no conflict of interest.

\section{ACKNOWLEDGEMENTS}

We express our deepest gratitude to the family for its participation in this study. This study was supported in part by the Centre National de la Recherche Scientifique (CNRS), the Agence Nationale de la Recherche (ANR), the Fondation LEJEUNE and by the Region Ile de France.

1 Verkerk AJ, Pieretti M, Sutcliffe JS et al: Identification of a gene (FMR-1) containing a CGG repeat coincident with a breakpoint cluster region exhibiting length variation in fragile X syndrome. Cell 1991; 3165: 905-914.

2 Chiurazzi P, Schwartz CE, Gecz J, Neri G: XLMR genes: update 2007. Eur J Hum Genet 2008; 16: 422-434.

3 Ropers $\mathrm{HH}$ : X-linked mental retardation: many genes for a complex disorder. Curr Opin Genet Dev 2006; 16: 260-269.

4 Chen W, Jensen LR, Gecz J et al: Mutation screening of brain-expressed X-chromosomal miRNA genes in 464 patients with nonsyndromic X-linked mental retardation. Eur J Hum Genet 2007; 15: 375-378.

5 Raymond FL, Tarpey P: The genetics of mental retardation. Hum Mol Genet 2006; 15 : R110-R116. Review.

6 Bauters M, Van Esch H, Marynen P, Froyen G: X chromosome array-CGH for the identification of novel X-linked mental retardation genes. Eur J Med Genet 2005; 48: 263-275.

7 Froyen G, Van Esch H, Bauters M et al: Detection of genomic copy number changes in patients with idiopathic mental retardation by high-resolution $\mathrm{X}$-array-CGH: important role for increased gene dosage of XLMR genes. Hum Mutat 2007; 28 : 1034-1042.

8 Madrigal I, Rodríguez-Revenga L, Armengol L et al: X-chromosome tiling path array detection of copy number variants in patients with chromosome X-linked mental retardation. BMC Genomics 2007; 8: 443

9 Colleaux L, Heuertz S, Molinari F, Rio M: Fluorescence genotyping for screening cryptic telomeric rearrangements. Methods Mol Biol 2002; 204: 181-189.

10 Romana SP, Cherif D, Le Coniat M, Derré J, Flexor MA, Berger R: In situ hybridization to interphase nuclei in acute leukemia. Genes chromosomes Cancer 1993; 8: 98-103.

11 Carrel L, Willard HF: an assay for $\mathrm{X}$ inactivation based on differential methylation at the fragile X locus, FMR 1. Am J Med Genet 1996; 58: 1111-1119.

12 Novelli A, Bernardini L, Salpietro DC et al: Disomy of distal Xq in males: case report and overview. Am J Med Genet 2007; 128: 165-169.

13 Cheng SF, Rauen KA, Pinkel D, Albertson DG, Cotter PD: Xq chromosome duplication in males: clinical, cytogenetic and array CGH characterization of a new case and review. Am J Med Genet A 2005; 135: 308-313.

14 Heard E: Recent advances in X-chromosome inactivation. Curr Opin Cell Biol 2004; 16: 247-255.

15 Van Esch H, Bauters M, Ignatius J et al: Duplication of the MECP2 region is a frequent cause of severe mental retardation and progressive neurological symptoms in males. Am J Hum Genet 2005; 77: 442-453.

16 Turner G, Lower KM, White SM et al: The clinical picture of the Börjeson-ForssmanLehmann syndrome in males and heterozygous females with PHF6 mutations. Clin Genet 2004; 65: 226-232.

17 Tarpey PS, Raymond FL, O'Meara S et al: Mutations in CUL4B, which encodes a ubiquitin E3 ligase subunit, cause an $\mathrm{X}$-linked mental retardation syndrome associated with aggressive outbursts, seizures, relative macrocephaly, central obesity, hypogonadism, pes cavus, and tremor. Am J Hum Genet 2007; 80: 345-352.

18 Wilson M, Mulley J, Gedeon A, Robinson H, Turner G: New X-linked syndrome of mental retardation, gynecomastia, and obesity is linked to DXS255. Am J Med Genet 1992; 44: 854-855.

19 Steinbach P, Horstmann W, Scholz W: Tandem duplication dup(X)(q13q22) in a male proband inherited from the mother showing mosaicism of X-inactivation. Hum Genet 1980; 54: 309-313.

20 Cremers FP, Pfeiffer RA, van de Pol TJ et al: An interstitial duplication of the $\mathrm{X}$ chromosome in a male allows physical fine mapping of probes from the Xq13q22 region. Hum Genet 1987; 77: 23-27.

21 Vejerslev LO, Rix M, Jespersen B: Inherited tandem duplication dup(X) (q131-q212) in a male proband. Clin Genet 1985; 27: 276-281.

22 Schwartz S, Schwartz MF, Panny SR, Peterson CJ, Waters E, Cohen MM: Inherited $\mathrm{X}$-chromosome inverted tandem duplication in a male traced to a grandparental mitotic error. Am J Hum Genet 1986; 38: 741-750.

23 Thode A, Partington MW, Yip MY, Chapman C, Richardson VF, Turner G: A new syndrome with mental retardation, short stature and an Xq duplication. Am J Med Genet 1988; 30: 239-250.

24 Yokoyama Y, Narahara K, Tsuji K et al: Growth hormone deficiency and empty sella syndrome in a boy with $\operatorname{dup}(X)$ (q13.3-q21.2). Am J Med Genet 1992; 42: 660-664.

25 Apacik $\mathrm{C}$, Cohen $\mathrm{M}$, Jakobeit $\mathrm{M}$ et al: Two brothers with multiple congenital anomalies and mental retardation due to disomy $(X)(q 12->q 13.3)$ inherited from the mother. Clin Genet 1996; 50: 63-73.

26 Shapira M, Dar H, Bar-EI H, Bar-Nitzan N, Even L, Borochowitz Z: Inherited inverted duplication of $X$ chromosome in a male: report of a patient and review of the literature. Am J Med Genet 1997; 72: 409-414.

27 Monaghan KG, Van Dyke DL, Feldman GL: Prader-Willi-like syndrome in a patient with an Xq23q25 duplication. Am J Med Genet 1998; 80: 227-231.

$28 \mathrm{Hol}$, Schepens MT, van Beersum SE et al: Identification and characterisation of an Xq26-q27duplication in a family with spina bifida and panhypopituitarism suggests the involvement of two distinct genes. Genomics 2000; 6: 174-181.

29 Solomon NM, Nouri S, Warne G, Lagerstrom-Fermer M, Forrest SM, Thomas PQ: Increased gene dosage at Xq26-q27 is associated with X-Linked hypopituitarism. Genomics 2002; 79: 553-559.

30 Solomon NM, Ross SA, Morgan T et al: Array comparative genomic hybridisation analysis of boys with $X$ linked hypopituitarism identifies a $3.9 \mathrm{Mb}$ duplicated critical region at Xq27 containing SOX3. J Med Genet 2004; 41: 669-678.

31 Jehee FS, Rosenberg C, Krepischi-Santos AC et al: An Xq22.3 duplication detected by comparative genomic hybridization microarray (Array-CGH) defines a new locus (FGS5) for FG syndrome. Am J Med Genet A 2005; 139: 221-226.

32 Bedeschi MF, Novelli A, Bernardini $L$ et al: Association of syndromic mental retardation with an $\mathrm{Xq12q13.1}$ duplication encompassing the oligophrenin 1 gene. Am J Med Genet A 2008; 146: 1718-1724.

33 Gabbett MT, Peters GB, Carmichael JM, Darmanian AP, Collins FA: Prader-Willi syndrome phenocopy due to duplication of Xq21.1-q21.31 with array CGH of the critical region. Clin Genet 2008; 73: 353-359.

34 Tzschach A, Chen W, Erdogan F et al: Characterization of interstitial Xp duplications in two families by tiling path array CGH. Am J Med Genet A 2008; 146: 197-203.

$35 \mathrm{Gecz} \mathrm{J}$, Baker E, Donnelly A et al: Fibroblast growth factor homologous factor 2 (FHF2): gene structure, expression and mapping to the Börjeson-Forssman-Lehmann syndrome region in Xq26 delineated by a duplication breakpoint in a BFLS-like patient. Hum Genet 1999; 104: 56-63. 
36 Lachlan KL, Collinson MN, Sandford RO, van Zyl B, Jacobs PA, Thomas NS: Functional disomy resulting from duplications of distal $\mathrm{Xq}$ in four unrelated patients. Hum Genet 2004; 115: 399-408.

37 Mattei JF, Mattei MG, Aumeras C, Auger M, Giraud F: X-linked mental retardation with the fragile X. A study of 15 families. Hum Genet 1981; 59: 281-289.

38 Peier AM, Mcllwain KL, Kenneson A, Warren ST, Paylor R, Nelson DL: (Over) correction of FMR1 deficiency with YAC transgenics: behavioral and physical features. Hum Mol Genet 2000; 9: 1145-1159.

39 Coulam C, Adamson SC, Annegers JF: Incidence of premature ovarian failure. Obstet Gynecol 1986; 67: 604-606.
40 Aittomäki K, Lucena JL, Pakarinen P et al: Mutation in the follicle-stimulating hormone receptor gene causes hereditary hypergonadotropic ovarian failure. Cell 1995; 82: 959-968.

41 Di Pasquale E, Beck-Peccoz P, Persani L: Hypergonadotropic ovarian failure associated with an inherited mutation of human bone morphogenetic protein-15 (BMP15) gene. Am J Hum Genet 2004; 75: 106-111.

42 Toniolo D: X-linked premature ovarian failure: a complex disease. Curr Opin Genet Dev 2006; 16: 293-300.

43 McConkie-Rosell A, Lachiewicz AM, Spiridigliozzi GA et al: Evidence that methylation of the FMR-I locus is responsible for variable phenotypic expression of the fragile X syndrome. Am J Hum Genet 1993; 53: 800-809. 